Pacific Journal of Mathematics

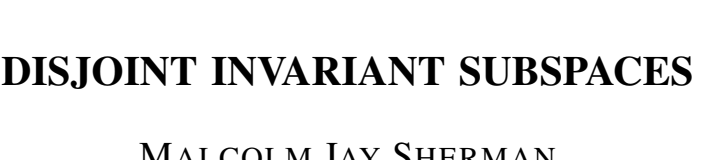




\section{DISJOINT INVARIANT SUBSPACES}

\section{MALCOLM J. SheRMAN}

Let $H_{\mathscr{C}}^{2}$ denote the (separable) Hilbert space of all functions $F\left(e^{i \theta}\right)$ defined on the unit circle with values in the separable (usually infinite dimensional) Hilbert space $\mathscr{H}$, and which are weakly in the Hardy class $H^{2}$. For a closed subspace of $H_{\mathscr{C}}^{2}$ "invariant"' means invariant under the right shift operator. Such an invariant subspace is said to be of full range if it is of the form $\mathscr{U} H_{\mathscr{C}}^{2}$, where $\mathscr{U}\left(e^{i \theta}\right)$ is a.e. a unitary operator on $\mathscr{C}$; i.e., an inner function. We show that if $\mathscr{H}$ is infinite dimensional there exists an uncountable family $\left\{\mathscr{H}_{\alpha}\right\}$ of invariant subspaces of $H_{\mathscr{K}}^{2}$ of full range such that $\mathscr{\mathscr { C }}_{\alpha} \cap \mathscr{M}_{\boldsymbol{\beta}}=(0)$ if $\alpha \neq \beta$.

This extends a theorem in the author's paper [2, p. 169] asserting the existence of two invariant subspaces $\mathscr{H}, \mathscr{N}$ of full range such that $\mathscr{C} \cap \mathscr{N}=(0)$. For basic definitions and notations consult [1], particularly Chapter VI.

For a bounded operator $T$ on $\mathscr{C},\|T\|<1$, define the Rota subspace $\mathscr{L}_{T}$ of $T$ to be all $F \in H_{\mathscr{C} C}^{2}$ with Fourier series $F=\sum_{k=0}^{\infty} \varphi_{k} e^{k i x}$ such that $\sum_{k=0}^{\infty} T^{k} \varphi_{k}=0$. It is known [2, p. 161] that $\mathscr{A}_{T}$ is of full range. It was shown in [2, p. 169] that if $T, U$ are-one-to one operators on $\mathscr{C}$ with disjoint ranges, then $\mathscr{L}_{T} \cap \mathscr{M}_{U}=(0)$. It suffices then to prove the existence in a separable infinite dimensional Hilbert space of an uncountable family of bounded one-to-one operators with disjoint ranges. To do this it suffices to exhibit an uncountable family of disjoint closed infinite dimensional subspaces of a separable Hilbert space, since the subspaces are then unitarily equivalent to the original space and the operators can be taken to be of the form $U / 2$, where $U$ is unitary as a mapping onto its range. It is convenient to describe such an example in $\mathscr{H}$ realized as $L_{\mathscr{K}}^{2}$, where $\mathscr{K}$ is some other Hilbert space. Let $\left\{e_{\alpha}\right\}$ be an uncountable family of pairwise linearly independent vectors in $\mathscr{K}$ (which exists if $\mathscr{K}$ is at least two-dimensional) and for the subspaces let

$$
\mathscr{N}_{\alpha}=\left\{F \in L_{\mathscr{X}}^{2}: F\left(e^{i x}\right)=f\left(e^{i x}\right) e_{\alpha}, \text { for some } f \in L^{2}\right\} .
$$

The situation when $\mathscr{H}$ is infinite dimensional thus contrasts strongly with the finite dimensional situation [1, p. 70] where the intersection of two invariant subspaces of full range also has full range, and the implication is that only when $\mathscr{C}$ is infinite dimensional can invariant subspaces of full range be pretty small. On the 
other hand, if nontrivial maximal invariant subspaces of $H_{\mathscr{H}}^{2}$ exist (or, equivalently, if there exist bounded operators on $\mathscr{P}$ without nontriviant subspaces [1, p. 103]), the existence of an uncountable family of disjoint maximal invariant subspaces is conceivable. For if there exists an operator $T$ on $\mathscr{C}$ without an invariant subspace, it may also happen that $T$ is not invertible and the codimension of the range of $T$ is uncountably infinite in the linear space sense. It is then almost certain that one can find an uncountable family of such operators whose ranges are disjoint.

\section{REFERENCES}

1. H. Helson, Lectures on Invariant Subspaces, Academic Press, New York, 1964.

2. M. J. Sherman, Operators and inner functions, Pacific J. Math. 22 (1967), 159-170.

Received November 15, 1967. The preparation of this paper was supported in part by NSF Grant GP-5497.

University of California, Los ANgeles 


\section{PACIFIC JOURNAL OF MATHEMATICS}

\section{EDITORS}

\section{H. ROYDEN}

Stanford University

Stanford, California

\section{J. Dugundu}

Department of Mathematics University of Southern California Los Angeles, California 90007

RICHARD ARENS

University of California Los Angeles, California 90024

ASSOCIATE EDITORS
E. F. Beckenbach
B. H. NEUMANN
F. WoLF
K. YosidA

\section{SUPPORTING INSTITUTIONS}

\author{
UNIVERSITY OF BRITISH COLUMBIA \\ CALIFORNIA INSTITUTE OF TECHNOLOGY \\ UNIVERSITY OF CALIFORNIA \\ MONTANA STATE UNIVERSITY \\ UNIVERSITY OF NEVADA \\ NEW MEXICO STATE UNIVERSITY \\ OREGON STATE UNIVERSITY \\ UNIVERSITY OF OREGON \\ OSAKA UNIVERSITY \\ UNIVERSITY OF SOUTHERN CALIFORNIA
}

STANFORD UNIVERSITY

UNIVERSITY OF TOKYO

UNIVERSITY OF UTAH

WASHINGTON STATE UNIVERSITY

UNIVERSITY OF WASHINGTON

AMERICAN MATHEMATICAL SOCIETY
CHEVRON RESEARCH CORPORATION
TRW SYSTEMS

AMERICAN MATHEMATICAL SOCIETY

TRW SYSTEMS

NAVAL WEAPONS CENTER

Mathematical papers intended for publication in the Pacific Journal of Mathematics should be in typed form or offset-reproduced, double spaced with large margins. Underline Greek letters in red, German in green, and script in blue. The first paragraph or two must be capable of being used separately as a synopsis of the entire paper. It should not contain references to the bibliography. Manuscripts, in duplicate if possible, may be sent to any one of the four editors. All other communications to the editors should be addressed to the managing editor, Richard Arens, University of California, Los Angeles, California 90024.

Each author of each article receives 50 reprints free of charge; additional copies may be obtained at cost in multiples of 50 .

The Pacific Journal of Mathematics is published monthly. Effective with Volume 16 the price per volume (3 numbers) is $\$ 8.00$; single issues, $\$ 3.00$. Special price for current issues to individual faculty members of supporting institutions and to individual members of the American Mathematical Society: $\$ 4.00$ per volume; single issues $\$ 1.50$. Back numbers are available.

Subscriptions, orders for back numbers, and changes of address should be sent to Pacific Journal of Mathematics, 103 Highland Boulevard, Berkeley 8, California.

Printed at Kokusai Bunken Insatsusha (International Academic Printing Co., Ltd.), 7-17, Fujimi 2-chome, Chiyoda-ku, Tokyo, Japan.

PUBLISHED BY PACIFIC JOURNAL OF MATHEMATICS, A NON-PROFIT CORPORATION

The Supporting Institutions listed above contribute to the cost of publication of this Journal, but they are not owners of publishers and have no responsibility for its content or policies. 


\section{Pacific Journal of Mathematics \\ Vol. 27, No. 3}

March, 1968

Charles A. Akemann, Invariant subspaces of $C(G) \ldots \ldots \ldots \ldots \ldots \ldots . \ldots 41$

Dan Amir and Zvi Ziegler, Generalized convexity cones and their duals ... . 425

Raymond Balbes, On ( $J, M, \mathrm{~m})$-extensions of order sums of distributive

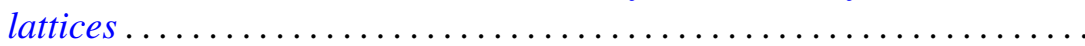

Jan-Erik Björk, Extensions of the maximal ideal space of a function algebra ........................................ 453

Frank Castagna, Sums of automorphisms of a primary abelian group ...... 463

Theodore Seio Chihara, On determinate Hamburger moment problems ..... .

Zeev Ditzian, Convolution transforms whose inversion function has complex

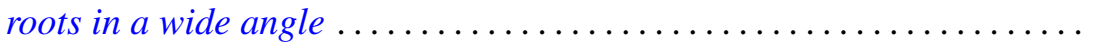

Myron Goldstein, On a paper of Rao .

Velmer B. Headley and Charles Andrew Swanson, Oscillation criteria for

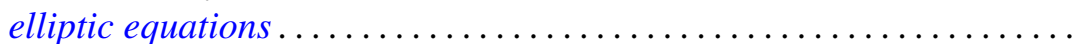

John Willard Heidel, Qualitative behavior of solutions of a third order nonlinear differential equation............................

Alan Carleton Hindmarsh, Pick's conditions and analyticity.............

Bruce Ansgar Jensen and Donald Wright Miller, Commutative semigroups

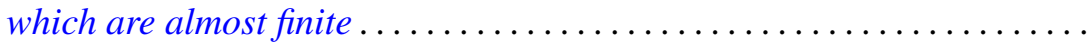

Lynn Clifford Kurtz and Don Harrell Tucker, An extended form of the

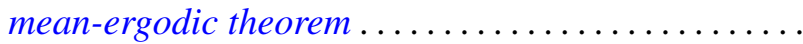

S. P. Lloyd, Feller boundary induced by a transition operator ...

Henry B. Mann, Josephine Mitchell and Lowell Schoenfeld, A new proof of the maximum principle for doubly-harmonic functions ...

Robert Einsohn Mosher, The product formula for the third obstruction ..

Sam Bernard Nadler, Jr., Sequences of contractions and fixed points ...

Eric Albert Nordgren, Invariant subspaces of a direct sum of weighted shifts...

Fred Richman, Thin abelian p-groups ...

Jordan Tobias Rosenbaum, Simultaneous interpolation in $\mathrm{H}_{2}$. II ...

Charles Thomas Scarborough, Minimal Urysohn spaces .

Malcolm Jay Sherman, Disjoint invariant subspaces..... .

Joel John Westman, Harmonic analysis on groupoids....

621

William Jennings Wickless, Quasi-isomorphism and TFM

Minoru Hasegawa, Correction to "On the convergence of resolvents of operators" 